(Volume 9, Number 10), not all interventions lend themselves to evidence-based or randomised control trial (RCT) evaluation. Their caution echoes that expressed by Davey Smith and Gordon, ${ }^{3}$ who point out that, when arguing for measures of health burdens such as poverty and inequity, it is not valid to demand an RCT-informed evidence base. The efficacy of health interventions at the individual level is appropriately addressed using RCTs, but the same is not true of population level policy measures. Evidence related to different national policy approaches exists, which supports the view that social and economic policies resulting in increased income inequalities are associated with poorer health outcomes. ${ }^{8,9}$ To dismiss this on the basis of the lack of supportive RCTs would be foolish.

\section{CONCLUSION}

It has been a privilege to be asked to comment on the Bulletin's child health series. The series demonstrates a child public health approach which is innovative, systematic, evidence-based, and sensitive to social and political contexts. I am sure that those involved in planning and executing these programs are acutely aware of some of the limitations and potential pitfalls I have considered. If linked with effective advocacy at local, state and national level, I am confident that these child health programs outlined in the series will contribute positively to the health of children in NSW. I am equally sure that the model for these programs will be invaluable to those who, like myself, are attempting to introduce a child public health agenda locally, nationally and internationally.

\section{REFERENCES}

1. Gilbert R. The changing epidemiology of SIDS. Arch Dis Child 1994; 70: 445-9.

2. Rose G. The strategy of preventive medicine. Oxford: Oxford University Press, 1992.

3. Davey Smith G, Gordon D. Poverty across the life course and health. In Pantazis C, Gordon D (editors) Tackling inequalities. Bristol: The Policy Press, 2000.

4. McKee M, Fulop N. On target for health? BMJ 2000; (320): 327-8

5. Marmot M, Wilkinson RG. Social determinants of health. Oxford: Oxford University Press, 1999.

6. Spencer NJ, Bambang S, Logan S, Gill L. Socioeconomic status and birthweight: comparison of an area-based measure with the Registrar General's social class. J Epidemiol Community Health 1999; (53): 495-98.

7. Cnattingius S, Ericson A, Gunnarskog J, Kallen B. A quality study of a Medical Birth Registry. Scand J Soc Med 1990; (18): 143-8.

8. Wilkinson RG. Unhealthy societies: the afflictions of inequality. London: Routledge, 1996.

9. Hewlett SA. Child neglect in rich nations. New York: UNICEF, 1993. F

\title{
CHILD HEALTH POLICY IN NSW: BUILDING ON A CENTURY OF CARE
}

\section{Caroline Wraith and Elisabeth Murphy \\ Health Services Policy Branch \\ NSW Department of Health}

The NSW child health policy framework is informed by a long and successful history of providing health services to children and their families, as well as recent policy developments at the national level. This article describes the background to the development of the NSW child health policy, The Start of Good Health: Improving the Health of Children in NSW, ${ }^{1}$ and provides information on NSW Health policy directions for child health.

\section{COMMUNITY CHILD HEALTH SERVICES IN NSW: A HISTORY}

The origin of community child health services in NSW is found in the infant welfare movement at the beginning of the 20th century. This movement was one of the most significant and successful public health initiatives, stemming from an awareness that children's health and welfare represented a particularly sensitive index of the wellbeing and progress of our society. At that time the issues were the high infant mortality rate associated with infectious disease and poor nutrition, and advocacy from mothers and grandmothers seeking support for the physical and nutritional needs of children. There was also recognition that poorer families could not afford medical advice for their children except in an emergency. The infant welfare movement played a major role in reducing the infant mortality rate, and led to the establishment of baby health services, which were the forerunner of our current child and family health services.

\section{Early innovations in care}

A study of these early services revealed considerable innovation in delivering flexible and responsive services 
to the community. ${ }^{2}$ For example, in the early 20 th century, trained health visitors were employed to visit, at home, the mothers of all new-born babies in the city of Sydney and surrounding industrial suburbs. These trained health visitors instructed mothers on proper feeding and hygienic care of their infants, and noted the living conditions for appropriate further action. Health visiting obtained dramatic results in reducing the infant mortality rate.

Another example of an innovative model of service delivery was found in the 1930s. A railway car was fitted as a travelling home for a nurse, with bedroom, bath, kitchenette with refrigeration, and with a large space furnished as a consulting room and clinic. The railway car travelled to rural centres, staying in each centre from two to ten days, as the work demanded. The service was extended by using local transport to reach towns beyond the station. The establishment of these Travelling Baby Clinics ensured that children and families in rural and remote areas of NSW, who most needed the services, received them. ${ }^{2}$

\section{Critical factors for success}

The success of children's health services over the last century has been the result of a number of critical factors. These include:

- securing the support of the public

- establishing partnerships with the community

- understanding the causes of ill health

- emphasising prevention

- the ongoing dedication and commitment of staff

- the flexibility of services

- a capacity to respond to changing social circumstances.

These same factors remain central to future progress in child health.

During the last 25 years, the focus of children's health care shifted again, as it came to be recognised that child health can be profoundly affected by social and family changes and new technologies. Child health services responded to these societal changes by increasing the range of services offered, reorientation of existing services, and further specialisation. With components coming from different public health, community health and hospital sector perspectives, this has meant that services have become increasingly specialised and more disparate. This has often resulted in poor coordination and communication between services.

\section{The last decade}

A number of initiatives in the 1990s started a process of bringing together the wide range of health services for children and young people. The development of the national Health Goals and Targets for Australian Children and Youth (1992), ${ }^{3}$ represented the first step in determining, across Australia, common aims and objectives for the development and provision of child health and youth health services. Five key goals were established as a starting point for planning to improve the health outcomes for Australian children and young people. These were:

- reducing the frequency of preventable mortality;

- reducing the impact of disability, including reductions in the occurrence of new disability and in the impact of established disabilities;

- reducing the incidence of vaccine-preventable diseases;

- reducing the impact of conditions occurring in adulthood which have their early manifestations in childhood or adolescence;

- enhancing family and social functioning.

The Health of Young Australians: A National Health Policy for Children and Young People, the first statement of national child and youth health principles and policy directions, followed in $1995 .{ }^{4}$ This was accompanied by an action plan, The National Health Plan for Young Australians, ${ }^{5}$ which was endorsed by Australian Health Ministers in 1996.

\section{MEASURING AND REPORTING ONTHE HEALTH OFYOUNG AUSTRALIANS}

An initiative that arose from the action plan was the development of a national information strategy for measuring and reporting on the health of young Australians. The Australian Institute of Health and Welfare (AIHW) was commissioned to develop this information framework to monitor the health of young Australians and to produce biennial reports on the health of children and young people. The National Child Health Information Framework, covers the main issues relevant to the 0-14 year age group, and forms the basis for monitoring and future reporting of child health information. The first national report on the health status of children in Australia was published by AIHW in 1998. Australia's Children 1998: Their Health and Wellbeing, ${ }^{6}$ provides comprehensive information from currently available sources of data on the health problems of children in Australia.

Health problems experienced by today's children reflect a complex interaction between children, their family, and 
their socioeconomic, political and cultural environments. Further coordination of activity across the health systemand more meaningful partnerships between health, education and welfare sectors - are needed if we are to maximise the opportunities to improve the health and wellbeing of children.

\section{THE NSW CHILD HEALTH POLICY}

In response to the national developments described above, and the need for increased collaboration between health and other sectors, NSW Health developed its first overarching child health policy. The child health policy The Start of Good Health: Improving the Health of Children in NSW was launched by the Minister for Health in October 1999.

The Start of Good Health policy provides a framework for the provision of services by NSW Health, for children 0-12 years, over the next five years. It brings together current knowledge of the health care needs of children in NSW, and identifies priorities and strategies for addressing those needs. It also acknowledges that children require specifically-designed health care services to meet their needs at each stage of their development. It further recognises that health services must become more responsive to the needs of parents for support in the important job of caring for children. The poorer health outcomes of children from socioeconomicallydisadvantaged families are highlighted, and the policy emphasises that health services must reach those with the greatest need.

The Start of Good Health identifies four goals for NSW Health. These are to:

- improve the health and wellbeing of children;

- improve the accessibility and appropriateness of health services for children;

- improve the quality of health services provided to children;

- promote partnerships within the health system and with other public and community-based agencies which impact on the health of children.

The NSW child health policy identifies and highlights examples of good practice and brings, within a single document, the range of initiatives aimed at improving the health of children. Priority health issues are identified, based on the Health Goals and Targets for Australian Children and Youth, and flexibility is promoted in the delivery of child health services, to include different settings such as family homes, child care centres, preschools and schools. Key interventions are identified for each developmental stage, which address a variety of health issues simultaneously and adopt a settings-based approach. The policy is also intended to assist in preparing the health system for the implementation of the Government's Families First strategy.

\section{CONCLUSION}

The directions of The Start of Good Health policy are supported by international research findings from the past three decades. This research has indicated that:

- early life experiences are vital to the growth and development of children;

- multiple health outcomes can result, for both parents and children, when parents have early support;

- prevention and early intervention services have the greatest effect on health, education and welfare when they cover a broad range of issues and are provided through a coordinated network.

The Start of Good Health draws on lessons from the past, recognises our achievements, and identifies directions for the future. The Start of Good Health provides the framework for reviewing and planning child health services in Area Health Services. It encourages active participation from all levels of NSW Health, and collaboration with other sectors, to focus on promoting the health and wellbeing of children and their families in NSW.

\section{REFERENCES}

1. NSW Health Department. The Start of Good Health: Improving the Health of Children in NSW. September 1999. Available on the internet at www.health.nsw.gov.au/healthpublic-affairs/publications/childhealth.

2. O'Connor, K. Our Babies: The State's Best Asset. A History of 75 Years of Baby Health Services in New South Wales. Sydney: NSW Department of Health, 1989.

3. Department of Health, Housing and Community Services. Health Goals and Targets for Australian Children and Youth. Canberra: AGPS, 1992.

4. Commonwealth Department of Health and Human Services. The Health of Young Australians: A National Health Policy for Children and Young People. Canberra: AGPS, 1995.

5. Commonwealth Department of Health and Family Services. The National Health Plan for Young Australians: An action plan to protect and promote the health of children and young people. Canberra: AGPS, 1997.

6. Australian Institute of Health and Welfare. Australia's children: their health and wellbeing 1998. AIHW Catalogue no. PHE 7. Canberra: AIHW, 1998. w 